\title{
Cultivo in vitro de somaclones de abacaxizeiro na presença de $\mathrm{NaCl}$
}

\author{
Lucila K. F. L. de Brito ${ }^{1}$, Gioconda E. D. D. Moura ${ }^{1}$, Camila P. Martins ${ }^{1}$, Magdi A. I. Aloufa ${ }^{1}$, \\ Cristiane E. C. Macedo ${ }^{1}$, Daniela B. Lopes ${ }^{2} \&$ Paulo A. V. Barroso ${ }^{3}$
}

\begin{abstract}
RESUMO
Neste trabalho foi avaliado o cultivo in vitro de somaclones de abacaxizeiro, na presença de elevadas concentrações de $\mathrm{NaCl}$. Propágulos de abacaxizeiro foram submetidos a um período de cultivo in vitro em diferentes concentrações de $\mathrm{NaCl}(0,12,5,25$ e $50 \mathrm{mM})$. Em seguida, foram cultivados na ausência do sal e, por fim, foram submetidos a um outro período de cultivo in vitro em 0 e $100 \mathrm{mM}$ de $\mathrm{NaCl}$. Não se observou interação entre as concentrações empregadas nos dois períodos de exposição ao $\mathrm{NaCl}$, de modo que propágulos provenientes de tratamentos com concentrações mais elevadas não apresentaram melhor desempenho durante o segundo período de exposição; no entanto, constatou-se alteração negativa para os valores referentes à maioria das variáveis avaliadas em propágulos cultivados na presença de $100 \mathrm{mM}$ de NaCl , na segunda exposição. Ao final do experimento foram selecionadas famílias cultivadas na presença de $100 \mathrm{mM}$ de $\mathrm{NaCl}$, com base na semelhança fenotípica ao controle. As famílias selecionadas eram originárias, igualmente, das quatro concentrações do primeiro período de tratamento com $\mathrm{NaCl}$. Desse modo, as concentrações empregadas no primeiro período de exposição ao $\mathrm{NaCl}$ não influenciaram significativamente o crescimento dos propágulos durante o segundo período de cultivo in vitro na presença de $\mathrm{NaCl}$.
\end{abstract}

Palavras-chave: Ananas comosus, estresse salino, crescimento, variação somaclonal

\section{Pineapple somaclones response to in vitro cultivation in presence of $\mathrm{NaCl}$}

\begin{abstract}
This study evaluated the in vitro cultivation of pineapple somaclones under high concentrations of $\mathrm{NaCl}$. Propagules of pineapple were cultivated in presence of different $\mathrm{NaCl}$ concentrations $(0,12.5,25$ and $50 \mathrm{mM})$, then passed through two subcultivations in absence of $\mathrm{NaCl}$, and finally submitted to a second in vitro cultivation under 0 and $100 \mathrm{mM}$ concentrations of $\mathrm{NaCl}$. Interactions between the concentrations of both treatment's periods were not observed. Hence, propagules proceeding from higher concentrations treatments did not show better performance during the second period. A negative response was observed for almost all studied variables by propagules grown in $100 \mathrm{mM} \mathrm{NaCl}$ in the second treatment period. At the end of the experimental period, some families cultivated in $100 \mathrm{mM} \mathrm{NaCl}$ were selected. These families came equally from the four concentrations of the first treatment period with $\mathrm{NaCl}$. Hence, the concentrations of $\mathrm{NaCl}$ applied in the first treatment period did not present significant influence on development of propagules during the second in vitro cultivation period under saline conditions.
\end{abstract}

Key words: Ananas comosus, salt stress, growth, somaclonal variation

\footnotetext{
UFRN, Av. Senador Salgado Filho s/n-. Lagoa Nova, CEP 59078-970 Natal, RN. Fone: (84) 32153424. Fax: (84) 32153425. E-mail: lucilabrito@yahoo.com.br; gioconda_moura@yahoo.com.br; alloufa@digi.com.br, camilapmartins@hotmail.com; cristianemacedo@ufrnet.br

${ }^{2}$ Embrapa - Centro de Pesquisa Agropecuária do Trópico Semi-Árido, CP 23, CEP 56300-970, Petrolina, PE. Fone: (87) 3862-1711. Fax: (87) $3862-1744$. E-mail: daniela@cpatsa.embrapa.br

${ }^{3}$ Embrapa Algodão, CP 174, CEP 58107-720, Campina Grande, PB. Fone: (83) 34133608, ramal: 2060. E-mail: pbarroso@cnpa.embrapa.br
} 


\section{INTRODUÇÃO}

Dá-se o nome de estresse salino ao quadro de alterações deletérias observado em plantas cultivadas em condições de salinidade (Xiong \& Zhu, 2001). Essas alterações ocorrem devido à intoxicação por íons e a diminuição da oferta de água e nutrientes à planta (Hasegawa et al., 2000). Plantas cultivadas em regiões tropicais de clima semi-árido estão mais sujeitas ao estresse salino, devido à elevada temperatura e à baixa pluviosidade, características dessas regiões, tais características associadas ao manejo inadequado da irrigação, favorecem a salinização dos solos (Reinhardt et al., 2001).

O cultivo de abacaxizeiro é uma atividade de destaque econômico em algumas regiões do Nordeste brasileiro, predominantemente nos tabuleiros costeiros. A Smooth Cayenne é uma das principais variedades de abacaxizeiro cultivadas no País e a maior parte de sua produção é destinada à industrialização e exportação (Cabral, 1999).

Uma alternativa para superação dos danos causados pela salinidade é o melhoramento de plantas, no qual se podem utilizar ferramentas não-convencionais para a indução de variabilidade genética (Borém, 2001). Dentre estas, a indução de variação somaclonal pode permitir a manipulação de grandes populações de células, sob condições ambientais controladas e em espaço reduzido, haja vista que a variação somaclonal se refere à variabilidade observada em plantas provenientes do cultivo in vitro. Uma vez obtida uma população in vitro geneticamente heterogênea, esta pode ser submetida à seleção pelo tratamento com um agente de pressão seletiva, como o $\mathrm{NaCl}$ (Duncan, 1997). Soneji et al. (2002), trabalhando com gemas dormentes da coroa de abacaxizeiro micropropagadas na presença de ANA e IBA, observaram a ocorrência de variantes somaclonais in vitro, tais como propágulos albinos, com folhas variegadas ou com caules estiolados. Em campo, 7,3\% das plantas se apresentaram amareladas, com folhas sem espinhos e raias de antocianina, enquanto que $0,6 \%$ tinham folhas espinhosas e ricas em antocianina.

A seleção in vitro pode atuar no melhoramento de plantas por meio da obtenção direta de genótipos de interesse ou, ainda, pela redução da população a ser selecionada em campo. Ambas as estratégias promovem o aceleramento de programas de melhoramento de plantas (Evans et al., 1984). Nos últimos anos, tem-se empregado a seleção in vitro no melhoramento de fruteiras visando ao desenvolvimento de diversas características que podem trazer benefícios à produção e ao consumo de frutas desses cultivares (Predieri, 2001). Tais trabalhos têm sido realizados tanto em monocotiledôneas como em eudicotiledôneas, como o abacateiro (González-Rosas et al., 2003), a mangueira (Jayasankar \& Litz, 1998) e o abacaxizeiro (Borrás et al., 2001); no entanto, o desenvolvimento de estratégias seletivas eficazes e a avaliação da eficiência da seleção in vitro são etapas indispensáveis para que sua aplicação seja vantajosa em programas de melhoramento.

Com o exposto, objetivou-se através deste trabalho, avaliar o cultivo in vitro de somaclones de abacaxizeiro na presença de elevadas concentrações de $\mathrm{NaCl}$ para, com isso, ob- servar o comportamento de explantes submetidos a uma pressão de seleção rápida ao $\mathrm{NaCl}$.

\section{MATERIAL E MÉTODOS}

Utilizaram-se propágulos de abacaxizeiro da variedade Smooth Cayenne provenientes do cultivo in vitro na presença de $\mathrm{NaCl}$. Estes foram cultivados em meio de cultura padrão, composto por macro e micronutrientes do meio MS (Murashige \& Skoog, 1962), vitaminas da mistura orgânica de White (White, 1951), $30 \mathrm{~g} \mathrm{~L}^{-1}$ de sacarose, 0,1 $\mathrm{mg} \mathrm{L}^{-1}$ de inositol, $0,1 \mathrm{~g} \mathrm{~L}^{-1}$ de benzilaminopurina (BAP) e $0,5 \mathrm{~g} \mathrm{~L}^{-1}$ de ácido naftalenoacético (ANA) (Medeiros et al., 2001). O meio foi geleificado com $6 \mathrm{~g} \mathrm{~L}^{-1}$ de agar e os propágulos mantidos sob fotoperíodo de $12 \mathrm{~h}$, iluminação de 2000 LUX e temperatura de $25^{\circ} \mathrm{C}$. Os subcultivos foram realizados a cada 30 dias.

Os propágulos provinham do cultivo in vitro nas concentrações de $\mathrm{NaCl}$ : 0, 12,5, 25 e 50 mM (primeira exposição). Em seguida, foram subcultivados duas vezes na ausência de $\mathrm{NaCl}$, a fim de diminuir o mascaramento da resposta ao tratamento devido a adaptações fisiológicas. Por fim, os propágulos das diferentes concentrações de $\mathrm{NaCl}$ foram distribuídos, dois a dois e aleatoriamente, nas concentrações de 0 e $100 \mathrm{mM}$ de $\mathrm{NaCl}$ (segunda exposição) passando por quatro subcultivos durante essa etapa. Foram avaliadas as seguintes variáveis a cada subcultivo realizado na segunda exposição: número de propágulos regenerados (maiores que $1 \mathrm{~cm}$ ) (NP); altura dos dois maiores propágulos (AP); comprimento (CP) e largura (LG) da folha mais jovem completamente expandida desses propágulos; e proporção entre matéria fresca e matéria seca (MF/MS).

O delineamento experimental foi inteiramente casualisado, em esquema fatorial $4 \times 2$, perfazendo um total de oito tratamentos. O número de repetições nos tratamentos variou entre dezesseis e vinte e sete. Cada repetição correspondia a um frasco de cultura, contendo, ao início do experimento, dois propágulos.

Os dados coletados foram submetidos à análise de variância. O teste de Tukey foi realizado sempre que o teste F indicou diferenças significativas entre os tratamentos. Também se estimaram e compararam os coeficientes de correlação de Pearson pelo teste t (Callegari-Jacques, 2003). A seleção dos propágulos in vitro teve por base a mediana da proporção entre as variáveis avaliadas, o que será descrito nos resultados.

\section{RESULTADOS E DISCUSSÃO}

De acordo com a análise de variância, as concentrações de $\mathrm{NaCl}$ utilizadas na primeira exposição ao sal geraram alterações significativas nos propágulos apenas na variável largura da folha. Já os propágulos cultivados nas concentrações usadas na segunda exposição, apresentaram significativamente médias diferentes entre si, em todas as variáveis avaliadas. Ainda, não houve interação significativa entre as concentrações da primeira e da segunda exposição (Tabela 1). 
Tabela 1. Análise de variância das variáveis número de propágulos regenerados $(\mathrm{NP})$, altura $(\mathrm{AP})$, comprimento $(\mathrm{CP})$ e largura $(\mathrm{LG})$ de propágulos da variedade $\mathrm{S}$. Cayenne subcultivados em na ausência e em presença de $100 \mathrm{mM}$ de $\mathrm{NaCl}$ (segunda exposição) apos um período de exposição a concentrações crescentes de $\mathrm{NaCl}(0$ a $50 \mathrm{mM}$ )

\begin{tabular}{|c|c|c|c|}
\hline Variáveis & FV & GL & QM \\
\hline \multirow{4}{*}{$N P^{1}$} & Primeira exposição (PE) & 3 & 0,14 \\
\hline & Segunda exposição (SE) & 1 & 11,22 ** \\
\hline & $\mathrm{PE} \times \mathrm{SE}$ & 3 & 0,23 \\
\hline & Resíduo & 280 & 0,28 \\
\hline \multirow{4}{*}{$\mathrm{CP}$} & Primeira exposição (PE) & 3 & 0,56 \\
\hline & Segunda exposição (SE) & 1 & 33,34 ** \\
\hline & PE $\times$ SE & 3 & 0,91 \\
\hline & Resíduo & 251 & 0,58 \\
\hline \multirow{4}{*}{ AP } & Primeira exposição (PE) & 3 & 1,10 \\
\hline & Segunda exposição (SE) & 1 & $107,65^{\star *}$ \\
\hline & PE x SE & 3 & 1,47 \\
\hline & Resíduo & 251 & 2,69 \\
\hline \multirow{4}{*}{ LG } & Primeira exposição (PE) & 3 & 0,10 \\
\hline & Segunda exposição (SE) & 1 & 1,01 ** \\
\hline & PE $\times$ SE & 3 & 0,06 \\
\hline & Resíduo & 251 & 0,02 \\
\hline \multirow{4}{*}{ MF/MS } & Primeira exposição (PE) & 3 & 21,32 \\
\hline & Segunda exposição (SE) & 1 & 203,20 ** \\
\hline & PE x SE & 3 & 11,44 \\
\hline & Resíduo & 182 & 29,77 \\
\hline
\end{tabular}

${ }^{1}$ Dados transformados por logaritmo $(x+0,5) ;{ }^{\star \star}$ Significativo ao nível de $1 \%$

De acordo com o Teste de Tukey, na segunda exposição, os propágulos cultivados na presença de $100 \mathrm{mM}$ de $\mathrm{NaCl}$ apresentaram, de modo geral, médias inferiores às observadas no controle para quase todas as variáveis estudadas (Tabela 2).

Tabela 2. Médias das variáveis número de propágulos regenerados $(\mathrm{NP})$, altura (AP), comprimento (CP), largura (LG) da folha e proporção entre matéria fresca e matéria seca (MF/MS) de propágulos da variedade $S$. Cayenne subcultivados em na ausência e em presença de $100 \mathrm{mM}$ de $\mathrm{NaCl}$ (segunda exposição) apos um período de exposição a concentrações crescentes de $\mathrm{NaCl}(0$ a $50 \mathrm{mM})$

\begin{tabular}{|c|c|c|c|c|c|c|}
\hline & $\mathrm{NaCl}(\mathrm{mM})$ & NP & $\mathrm{CP}$ & AP & LG & MF/MS \\
\hline \multirow{4}{*}{$1^{\mathrm{a}}$ Exposição } & 0 & 25,67 & 3,06 & 5,19 & $0,53 \mathrm{a}$ & 20,02 \\
\hline & 12,5 & 26,67 & 3,01 & 4,92 & $0,50 \mathrm{a}$ & 20,36 \\
\hline & 25 & 23,29 & 2,98 & 4,91 & $0,48 a b$ & 18,62 \\
\hline & 50 & 21,49 & 2,80 & 5,07 & $0,41 \mathrm{~b}$ & 19,54 \\
\hline \multirow{2}{*}{$2^{\mathrm{a}}$ Exposição } & 0 & $35,48 \mathrm{a}$ & $3,42 \mathrm{a}$ & $5,81 \mathrm{a}$ & $0,40 \mathrm{~b}$ & $20,92 \mathrm{a}$ \\
\hline & 100 & $13,07 \mathrm{~b}$ & $2,52 \mathrm{~b}$ & $4,23 \mathrm{~b}$ & $0,56 \mathrm{a}$ & $18,36 \mathrm{~b}$ \\
\hline
\end{tabular}

Médias seguidas de letras distintas são diferentes, segundo o teste de Tukey $(p<0,05)$

A ausência de interação entre as concentrações dos dois períodos de exposição e o crescimento inferior dos propágulos submetidos a $10 \mathrm{mM}$ de $\mathrm{NaCl}$, torna evidente que propágulos inicialmente expostos a tratamentos com $\mathrm{NaCl}$ a 12,5, 25 e 50 mM não tiveram comportamento distinto daqueles provenientes do tratamento controle. A simples exposição ao sal, mesmo nas concentrações mais elevadas, não foi eficiente para a seleção de famílias de plantas mais resistentes ao estresse salino, uma vez que a exposição a
100 mM de $\mathrm{NaCl}$ causou à redução do número e do desenvolvimento dos propágulos provenientes de todos os tratamentos. Isso pode ser atribuído ao uso de uma concentração de sal (100 mM), acima do limite de resistência que possa ter sido induzida pelo pré-tratamento salino ou, ainda, devido à inexistência de indução de pressão seletiva pelas concentrações aplicadas na primeira exposição. Medeiros et al. (2001), trabalhando com propágulos das variedades Smooth Cayenne e Pérola, observaram queda na multiplicação a partir da concentração de $12,5 \mathrm{mM}$ de $\mathrm{NaCl}$.

A redução do número de propágulos pode estar relacionada a fenômenos associados ao estresse salino, como retardo no aparecimento e atrofiamento das gemas além de alteração na divisão e expansão celular (Larcher, 2001; Xiong \& Zhu, 2001); porém, não foram observados sintomas de intoxicação salina, tais como necrose dos brotos regenerados ou de suas extremidades. Desse modo, nem mesmo a concentração de $100 \mathrm{mM}$ de $\mathrm{NaCl}$ causou danos fisiológicos severos que levassem a morte de brotos. Essa resposta pode estar relacionada à resistência moderada do abacaxizeiro observada em campo, que está sendo expressa in vitro.

A ausência de necrose generalizada ou difusa nos brotos limitou o uso de uma estratégia de seleção rápida, na qual os sobreviventes são selecionados. Cruz \& Regazzi (2001) indicaram a utilização de variáveis correlacionadas como método eficiente à identificação de indivíduos superiores, uma vez que auxiliam na observação do estado geral da planta. Porém, pela observação dos coeficientes de correlação obtidos, observa-se uma ocorrência de correlações fracas ou relativamente fracas, entre os caracteres. Desse modo, o uso da correlação como parâmetro não pôde ser utilizado como estratégia de seleção (Tabela 3).

Tabela 3. Correlações entre os caracteres número de propágulos regenerados $(\mathrm{NP})$, altura $(\mathrm{AP})$, comprimento $(\mathrm{CP})$, largura $(\mathrm{LG})$ da folha e proporção entre matéria fresca e matéria seca (MF/MS) avaliados no abacaxizeiro variedade Smooth Cayenne cultivado in vitro, segundo a concentração de $\mathrm{NaCl}$ presente no meio de cultura (0 mM e $100 \mathrm{mM}$ )

\begin{tabular}{cccccc}
\hline Concentração & Caráter & NP & CP & AP & LG \\
& CP & 0,18 & & & \\
0 & AP & 0,13 & $0,43 * *$ & & \\
& LG & 0,09 & $0,45^{* *}$ & 0,24 & \\
& MF/PM & $-0,02$ & $-0,14$ & $-0,02$ & $-0,13$ \\
& CP & $0,39 * *$ & & & \\
& AP & $0,44^{* *}$ & $0,77^{* *} \mathrm{a}$ & & \\
& LG & $0,18^{* *}$ & $0,39 * * a$ & $0,35^{* *}$ & \\
& MF/PM & $0,32 * *$ & 0,11 & $0,19 *$ & $0,18 *$ \\
\hline
\end{tabular}

* Significativo ao nível de 1\%; ** Significativo ao nível de $5 \%$ "a" representa coeficientes de correlação significativamente diferentes dos coeficientes de correlação verificados nas plantas tratadas com $0 \mathrm{mM}$ de $\mathrm{NaCl}$, segundo 0 teste $\mathrm{t}(\mathrm{p}<0,05)$

Por meio da análise visual, puderam ser identificadas alterações na arquitetura de propágulos cultivados na presença de $\mathrm{NaCl}$ (Figura 1). Também foi observada a redução no comprimento das folhas em alguns propágulos cultivados na presença de $100 \mathrm{mM}$ de $\mathrm{NaCl}$, o que levou a alteração na arquitetura desses em relação ao controle. Com essas observações, tornou-se evidente a desvantagem de uma seleção 
baseada em caracteres individuais aparentemente positivos (ou seja, famílias com propágulos maiores ou maior número de propágulos). Esse procedimento não asseguraria a seleção de indivíduos com arquitetura semelhante àqueles cultivados na ausência de $\mathrm{NaCl}$, ou seja, que não apresentassem alterações no aspecto morfológico (arquitetura do propágulo) que pudessem estar relacionadas ao estresse salino. Assim, desenvolveu-se uma metodologia de seleção baseada na semelhança fenotípica entre propágulos cultivados na presença e os cultivados na ausência de $\mathrm{NaCl}$ na segunda exposição.

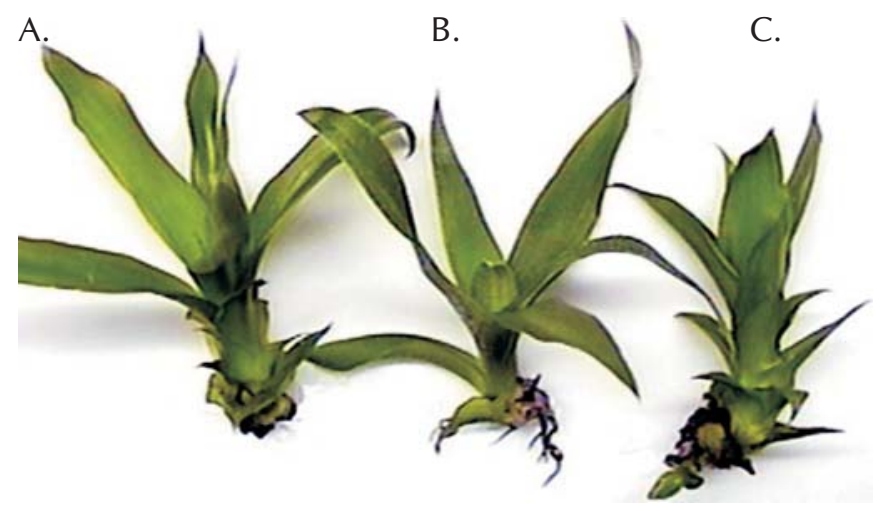

Figura 1. Comparação entre propágulos de abacaxizeiro da variedade Smooth Cayenne regenerados em diferentes concentrações de $\mathrm{NaCl}$. A propágulo regenerado em $0 \mathrm{mM}$; B - propágulo selecionado regenerado em $100 \mathrm{mM}$; C - propágulo não selecionado regenerado em $100 \mathrm{mM}$

Para isso, a seleção dos propágulos se deu a partir da proporção entre os caracteres fenotípicos avaliados (número de propágulos regenerados, altura dos dois maiores propágulos, comprimento e largura da folha mais jovem completamente expandida desses propágulos e proporção entre matéria fresca e matéria seca). Os caracteres avaliados foram relacionados dois a dois, obtendo-se ao todo, dez razões para cada família. As famílias que, na concentração de $100 \mathrm{mM} \mathrm{NaCl}$, apresentassem proporções semelhantes àquelas observadas no controle, foram consideradas resistentes; esta seleção teve, por base, o valor da mediana das razões obtidas para cada tratamento. As famílias que apresentaram pelo menos seis proporções similares ao controle foram selecionadas (Tabela 4). Desse modo, foram selecionadas 35,6\% das famílias cultivadas em $100 \mathrm{mM}$ de $\mathrm{NaCl}$. De acordo com o teste $\mathrm{X}^{2}$, as concentrações a que os propágulos haviam sido previamente submetidos, não foram importantes na seleção $\left(X^{2}=5,01, p>0,17\right)$. Ou seja, proporções semelhantes de propágulos selecionados provinham das concentrações da primeira exposição ao $\mathrm{NaCl}$. Esses resultados apontam, mais uma vez, que a simples exposição ao $\mathrm{NaCl}$ não permitiu a seleção de somaclones superiores.

A seleção com base na mediana das razões de cada tratamento não indica ocorrência de variação somaclonal de caráter herdável (genética), mas, apenas a ocorrência de famílias com performance superior em função de apresentarem arquitetura semelhante ao das cultivadas na ausência de $\mathrm{NaCl}$. Esse desempenho pode estar ou não relacionado a uma variação herdável, porém, em virtude dos propágulos utilizados serem provenientes de um longo período de cultivo in vitro, cerca de três anos, é provável que tenha havido variação somaclonal anterior à execução do experimento. Segundo Duncan (1997), a ocorrência de variação somaclonal pode ser estimulada pelo cultivo in vitro prolongado e esta pode ter sido exposta à triagem pelo cultivo na presença de $\mathrm{NaCl}$ na segunda exposição e ser responsável pela arquitetura observada nas famílias selecionadas.

Além de avaliar a origem dos caracteres selecionados, é oportuna a confirmação da superioridade, isto é, deve-se verificar se a semelhança com a arquitetura dos propágulos controle confere alguma vantagem ao cultivo na presença de $\mathrm{NaCl}$. Uma vez que, é sabido que algumas espécies permanecem com o crescimento inalterado na presença de $\mathrm{NaCl}$, porém o tempo de sobrevivência é comprometido. Outras sobrevivem por longos períodos, mas a queda no metabolismo decorrente da exposição prolongada ao $\mathrm{NaCl}$ compromete o seu desenvolvimento (Xiong \& Zhu, 2001).

Tais estudos podem ser realizados na condição in vitro ou in vivo, haja vista que dados da literatura indicam que desempenhos observados in vitro podem ter ou não correlação com a resposta vegetal numa condição ex vitro. Bajji et al. (1998) não encontraram correspondência evidente entre o comportamento fisiológico em calos e tecidos de plantas adultas de Atriplex halimus. Lutts et al. (1996), por outro lado, constataram boa correlação entre calos e plantas de arroz para assimilação de nutrientes minerais, ajustamento osmótico e acúmulo de prolina. Barroso et al. (2003), trabalhando com abacaxizeiro, notaram que plantas micropropagadas na presença e na ausência de $\mathrm{NaCl}$ indicaram taxas de crescimento semelhantes quando aclimatadas mas diferiram em relação às variâncias fenotípicas; portanto, os somaclones selecionados devem passar por uma avaliação em campo para se avaliar: a estabilidade dos caracteres, a sobrevivência, o desenvolvimento e a produtividade dos somaclones selecionados.

Tabela 4. Amostra da seleção realizada, baseada nas medianas dos caracteres número de propágulos regenerados (NP), altura (AP), comprimento (CP) e largura (LG) de propágulos da variedade "Smooth Cayenne" subcultivados em 0 mM e 100 mM de NaCl

\begin{tabular}{cccccccccccc}
\hline NaCI (mM) & Famílias & CP/NP & AP/NP & LG/NP & REL/NP & CP/AP & CP/LG & CP/RELI & AP/LG & AP/LG & LG/REL \\
0 & & $\underline{0,0920}$ & $\underline{0,150}$ & $\underline{0,0096}$ & $\underline{0,446}$ & $\underline{0,659}$ & 2,500 & $\underline{0,166}$ & 13,607 & 0,261 & $\underline{0,0185}$ \\
& 1 & 0,110 & 0,300 & 0,018 & 1,000 & 0,599 & 1,800 & 0,150 & 8,000 & 0,200 & 0,050 \\
& 2 & 0,200 & 0,300 & 0,037 & 0,920 & 0,600 & 1,200 & 0,130 & 7,000 & 0,230 & 0,020 \\
& 3 & $\underline{0,100}$ & 0,300 & $\underline{0,009}$ & $\underline{0,500}$ & $\underline{0,650}$ & 1,700 & $\underline{0,170}$ & 12,000 & 0,230 & 0,030 \\
100 & & 0,138 & 0,304 & 0,064 & 0,113 & 0,427 & 2,083 & 0,700 & 4,923 & 0,175 & 0,035 \\
\hline
\end{tabular}

Os valores sublinhados correspondem aos valores semelhantes ao controle nas famílias selecionadas 


\section{CONCLUSÕES}

1. Propágulos de abacaxizeiro provenientes do cultivo in vitro em elevadas concentrações de $\mathrm{NaCl}$ não apresentaram um melhor desempenho em um segundo período de tratamento salino in vitro.

2. A semelhança na arquitetura de propágulos com os do controle foi utilizada na seleção de $35,6 \%$ das famílias de propágulos de abacaxizeiro expostas a $100 \mathrm{mM} \mathrm{NaCl}$.

\section{AGRADECIMENTOS}

O presente trabalho foi realizado com apoio do CNPq, Conselho Nacional de Desenvolvimento Científico e Tecnológico - Brasil.

\section{LITERATURA CITADA}

Bajji, M.; Kinet, J. M.; Lutts, S. Salt stress effects on roots and leaves of Atriplex halimus L. and their correspondig callus cultures. Plant Science, v.137, n.2, p.131-142, 1998.

Barroso, P. A. V.; Moura, G. E. D. D.; Brito, L. K. F. L.; Martins, C. P.; Macedo, C. E. C.; Lopes, D. B.; Alloufa, M. A. I. Efeito do cultivo in vitro na presença de $\mathrm{NaCl}$ em plantas de abacaxizeiro na fase de aclimatação. Revista Brasileira de Engenharia Agrícola e Ambiental, Campina Grande, v.7, n.3, p.473-477, 2003.

Borém, A. Melhoramento de plantas. 3.ed. Viçosa: UFV, 2001. 500p.

Borrás, O.; Santos, R. M.; Matos, A. P.; Cabral, R. S.; Arzola, M. A first attempt to use a Fusarium subglutinans culture filtrate for the selection of pineapple cultivars resistant to fusariose disease. Plant Breeding, Halle, v.120, n.1, p.435-438, 2001.

Cabral, J. R. S. Cultivares de abacaxi. Cruz das Almas: Embrapa Mandioca e Fruticultura, 1999, 20p. Circular Técnica, 33

Callegari-Jacques, S. M. Bioestatística: Princípios e aplicações. 1.ed. Porto Alegre: Artmed, 2003. 255p.

Cruz, C. D.; Regazzi, A. J. Modelos biométricos aplicados ao melhoramento genético. 3.ed. Viçosa: UFV, 2001. 480p.

Duncan, R. R. Tissue culture-induced variation and crop improvment. Advances in Agronomy, New York, v.58, n.2, p.201239, 1997.
Evans, D. A., Sharp, W. R., Medina-Filho, H. P. Somaclonal and gametoclonal variation. American Journal of Botany, Columbus, v.71, n.6, p.759-774, 1984.

Gonzáles-Rosas, H.; Salazar-Garcia, S.; Ramírez-Reyes, G.; Rodriguez-Ontiveros, J. L.; Rao, P. S.; Ramos-Villasenor, A. C. Preliminary results of in vitro selection for tolerance to chloride excess in avocado. Revista Chapingo, Texcoco, v.9, n.1, p.39-43, 2003.

Hasegawa, P. M.; Bressan, R. A.; Zhu, J.; Bohnert, H. J. Plant cellular and molecular responses to high salinity. Annual Review of Plant Physiology and Plant Molecular Biology, Palo Alto, v.51, n.1, p.463-499, 2000.

Jayasankar, S.; Litz, R. E. Characterization of embryogenic mango cultures selected for resistance to Colletotrichum gloeosporioides culture filtrate and phytotoxin. Theoretical and Applied Genetics, Berlin, v.96, n.6-7, p.823-831, 1998.

Larcher, W. Ecofisiologia vegetal. 1.ed. São Carlos: Rima, 2001. 531p.

Lutts, S.; Kinet, J. M.; Bouharmont, J. Effects of various salt and of manitol on ion and proline accumulation in relation to osmotic adjustment in rice (Oryza sativa L.) callus cultures. Journal of Plant Physiology, Heidelberg, v.149, n.1-2, p.186-195, 1996.

Medeiros, D. N.; Macedo, C. E. C.; Alloufa, M. A. I. Efeito do $\mathrm{NaCl}$ sobre a multiplicação in vitro do abacaxizeiro (Ananas comosus (L.) Merr). Revista Brasileira de Fruticultura, Jaboticabal, v.11, n.1,p.21-28, 2001.

Murashige, T.; Skoog, F. A revised medium for rapid growth and bioassays with tobacco tissue culture. Physiology Plantarum, Copenhagen, v.15, n.1, p.473-497, 1962.

Predieri, S. Mutation induction and tissue culture in improving fruits. Plant Cell, Tissue and Organ Culture, Amsterdam, v.64, n.2-3, p.185-210, 2001.

Reinhardt, D. H.; Souza, L. F. d. S.; Cabral, J. R. S. Abacaxi irrigado em condições semi-aridas. 1.ed. Cruz das Almas: Embrapa Mandioca e Fruticultura, 2001.108p.

Soneji, J. R.; Rao, P. S.; Mhatre, M. Somaclonal variation in micropropagated dormant axillary buds of pineapple (Ananas comusus L., Merr.). Journal of Horticultural Science and Biotechnology, Coventry, v.77, n.1, p.28-32, 2002.

White, P. R. Nutritional requirements of isolated plant tissues and organs. Annual Review of Plant Physiology, Heidelberg, v.2, n.1, p.231-244, 1951.

Xiong, L.; Zhu, J. Molecular and genetic aspects of plant responses to osmotic stress. Plant, Cell and Environment, Nottingham, v.25, n.2, p.131-139, 2001. 